\title{
Role of common bile duct resection in T2 and T3 gallbladder cancer patients
}

\author{
Jin Hong Lim ${ }^{1}$, Jae Uk Chong ${ }^{2}$, Sung Hoon $\mathrm{Kim}^{3}$, Seung Woo Park ${ }^{4}$, \\ Jin Sub $\mathrm{Choi}^{2}$, Woo Jung $\mathrm{Lee}^{2}$, and Kyung Sik Kim²
}

\begin{abstract}
${ }^{1}$ Department of Surgery, Gangnam Severance Hospital, Yonsei University College of Medicine, Seoul,
${ }^{2}$ Department of Surgery, Severance Hospital, Yonsei University College of Medicine, Seoul,

${ }^{3}$ Department of Surgery, Wonju Severance Christian Hospital, Yonsei University College of Medicine, Wonju,

${ }^{4}$ Department of Internal Medicine, Severance Hospital, Yonsei University College of Medicine, Seoul, Korea
\end{abstract}

Backgrounds/Aims: Routine bile duct resection as part of the typical oncological resection for patients with advanced gallbladder cancer remains controversial with regard to, ultimately, curative value. The aim of this study was to compare oncological outcomes for patients undergoing surgery for gallbladder cancer with or without bile duct resection. Methods: We recruited, for the purpose of this study, all patients who underwent surgical resection for T2 and T3 gallbladder cancer at Severance hospital, Seoul, Korea, during the period January 2000 and December of 2011. The patient data was reviewed retrospectively. Results: The patients $(n=149)$ recruited to participate in the study were divided into two groups according to their bile duct resection status: The bile duct resection group (BDR group, $n=54$ ); and, the bile duct non-resection group (BDNR group, $n=95$ ). Significant difference was found in lymph node retrieval between BDR and BDNR groups ( 15 vs. 5 , respectively with $p<0.001)$. There was no significant difference between the two groups with regard to the five year survival rate ( $43 \%$ in BDR group vs. $57 \%$ in BDNR group, $p=0.339)$. Following multivariate analysis, lymph node metastasis, advanced T-stage, and total retrieved lymph nodes $<6$ were independent prognostic factors for poor survival in patients with T2 and T3 gallbladder cancer. Conclusions: The findings revealed by the current study suggest that the role of bile duct resection might be limited to improved staging, and offers no advantage in long-term survival. However, in view of the foregoing and given the minimal increase in morbidity associated with BDR, it should be actively considered as a treatment option for patients who present with findings suspicious for invasion around hepatoduodenal ligament. (Ann Hepatobiliary Pancreat Surg 2018;22:42-51)

Key Words: Gallbladder neoplasms; Common bile duct; Survival rate; Prognosis

\section{INTRODUCTION}

Gallbladder adenocarcinoma, historically, has been considered an incurable malignancy with a dismal prognosis. ${ }^{1,2}$ Complete surgical resection seems to represent the only potentially effective curative treatment for resectable gallbladder cancer. Regional lymph node dissection is indispensable and invaluable for the accurate staging of gallbladder cancer. ${ }^{3,4}$ The extent of resection in gallbladder cancer is usually determined by the pre- and intraoperative assessment of the nature and extent of the tumor invasion. According to the National Comprehensive Cancer Network (NCCN) guidelines, ${ }^{5}$ simple cholecystectomy is considered appropriate to treat T1a gallbladder cancer. In patients with more advanced localized disease, en bloc hepatic resection and lymphadenectomy are recommended. ${ }^{5}$ Whether routine bile duct resection is medically indicated and "should be performed", in many cases, remains a judgment call on the part of the surgeon because the surgical indication may remain unclear, even to direct inspection. There is a lack of objective evidence to support an increased long-term survival rate after routine resection, while increased morbidity has been reported. ${ }^{6-8}$ Several recent studies have focused on identifying prognostic factors conductive to long-term survival in those patients afflicted with advanced gallbladder cancer. Although several varia-

Received: March 4, 2017; Revised: September 7, 2017; Accepted: September 17, 2017

Corresponding author: Kyung Sik Kim

Department of Surgery, Yonsei University College of Medicine, 50 Yonsei-ro, Seodaemun-gu, Seoul 03722, Korea Tel: +82-2-2228-2125, Fax: +82-2-313-8289, E-mail: kskim88@yuhs.ac

Copyright (C) 2018 by The Korean Association of Hepato-Biliary-Pancreatic Surgery

This is an Open Access article distributed under the terms of the Creative Commons Attribution Non-Commercial License (http://creativecommons.org/ licenses/by-nc/4.0) which permits unrestricted non-commercial use, distribution, and reproduction in any medium, provided the original work is properly cited. Annals of Hepato-Biliary-Pancreatic Surgery - pISSN: 2508-5778 - elSSN: 2508-5859 
bles such as lymphovascular invasion, the operative method and total lymph node count of $<6$ have been proposed no definitive consensus has ever been achieved. ${ }^{3,9,10}$

Current guidelines ${ }^{5}$ suggest that a selective approach to bile duct resection be implemented and utilized, with the aim of ensuring a negative margin. Despite the relative paucity of rarified, substantial medical evidence, others recommend routine bile duct resection in an effort to increase chances of disease-free survival. ${ }^{9}$ The aim of this study was to more precisely assess and identify the role of bile duct resection for $\mathrm{T} 2$ and $\mathrm{T} 3$ gallbladder cancer, vis-à-vis the specific issues of oncological and long-term survival benefit.

\section{MATERIALS AND METHODS}

\section{Patients}

For the purpose of this study, all patients who underwent surgical resection for documented diagnoses of gallbladder cancer at the Severance hospital, Seoul, Korea during the period January 2000 through December of 2011 were identified. Patients were included for further analysis if the pathological and surgical report confirmed T2 or T3 gallbladder cancer, and an R0 margin. The patients recruited for the study were divided into two groups: The bile duct resected (BDR group); and, the bile duct non-resected group (BDNR group). Formal comparison was made between the clinicopathologic characteristics and the follow-up data referable to the patients in each of the two groups.

\section{Preoperative studies}

All patients underwent preoperative abdominal ultrasonography and computed tomography. Endoscopic ultrasonography was used to identify and assess the degree of penetration of the focal malignancy into the gallbladder wall in patients with suspected invasive lesions. Positron emission tomography was performed to evaluate distant metastases after laparoscopic or open cholecystectomy in patients with incidentally-diagnosed gallbladder cancer. Blood levels of carbohydrate antigen 19-9 (CA 19-9) were evaluated as a tumor marker. The medical history of each participant patient was scrutinized, and all patients underwent physical examinations, baseline laboratory testing, electrocardiography and chest imaging.

\section{Surgical strategy}

The standard surgical procedure undertaken was radical cholecystectomy (involving cholecystectomy and segment $4 \mathrm{~b} / 5$ liver resection around the gallbladder bed), with a margin of approximately $2 \mathrm{~cm}$. However, some surgeons did not perform liver resections (in those cases where intraoperative inspection and the findings did not reveal gross liver invasion). Lymph node (LN) dissection was classified as either "D1" or "D2" dissection. The D1 was defined as "dissection around the hepatoduodenal ligament (including LN removal around the cystic duct, bile duct, portal vein, and hepatic artery) and dissection of LNs around the gastrohepatic ligament". The D2 dissection was defined as "D1 dissection plus dissection of the celiac LNs, pancreaticoduodenal LNs, and para-aortic LNs". Although the extent of lymph node dissection often depended on a judgement call by the individual surgeon, D1 dissection was routinely performed by all surgeons. Dissection of para-aortic lymph nodes and other nodes belonging to the N2 group were usually conducted when lymph node enlargement was observed intraoperatively. Para-aortic lymph nodes were excluded from the total lymph node count. The nature and extent of additional or combined resection was determined by tumor extent. Decision regarding bile duct resection depended on the surgeons' visual and tactile assessment in the operating room. During the study period within the institution, no consensus was achieved among the surgeons regarding the issue of "routine" bile duct resection. Due to the lack of consensus, some surgeons performed routine bile duct resection, while others opted to perform the procedures which they considered medically reasonable and necessary based upon dynamic assessment of the intraoperative findings during the actual surgery. Regardless, we also noted that complete clearance of the hepatoduodenal ligament including bile duct resection, was always performed in the patients with positive cystic duct resection margins, as well as those patients suspected to have direct invasion around the hepatoduodenal ligament as identified in preoperative imaging studies.

\section{Perioperative and follow-up data}

During surgery, operative procedures, operative time, intraoperative blood loss and transfusion requirement were carefully documented. Complications were registered ac- 
cording to the Clavien-Dindo Classification of Surgical Complications. ${ }^{11}$ Patients with advanced T-stage $(\mathrm{T} \geq 3)$ or lymph node metastasis $(\mathrm{N} \geq 1)$ were recommended for adjuvant chemotherapy, radiotherapy, or chemoradiation therapy. Patients were referred to medical oncologists, and each oncologist chose a different treatment regimen according to experience and preference. The adjuvant therapy was not provided if the patient declined the treatment, or if the patient's performance status was greater than two based on the Eastern Cooperative Oncology Group guidelines. CA 19-9 levels were checked as a tumor marker, and an abdominal-pelvic computed tomography scan was performed at three months postoperative. If and when tumors recurred, chemotherapy and/or radiation therapy were initiated dependent upon patient status. Local recurrence of tumors, such as the trocar site recurrence, was controlled by surgical excision. The tumor recurrences were categorized as "local recurrences" or "distant metastases". The documented date of the last follow-up was set at January 2015.

\section{Statistical analysis}

For each quantitative variable, the Shapiro-Wilk test was used as a test of normality. Continual data were compared using Student's t-test or Mann-Whitney U test, as appropriate. Categorical variables were compared using the Chi-square test or Fisher's exact test, as appropriate. Survival curves were calculated by the Kaplan-Meier method; differences in the survival curves were compared by the log-rank test. Multivariate analysis identified prognostic factors of survival using the Cox proportional hazard model. Statistical analyses were performed with Statistical Package for the Social Sciences v.20 software (IBM-SPSS Inc., Chicago, IL USA). Statistical significance was defined by $p$-values $<0.05$.

\section{RESULTS}

Of the 271 patients who underwent surgery for gallbladder cancer within the study period, 211 (78\%) patients underwent R0 resection. Of these 211 patients, 149 (55\%) had $\mathrm{T} 2$ or $\mathrm{T} 3$ disease confirmed pathologically and were included for further analysis (Fig. 1).

Clinicopathologic characteristics of patients divided into BDR group and BDNR group are summarized in Table
1. Eighty-nine patients $(60 \%)$ received liver resection; of these subjects, $73(49 \%)$ received partial or complete resection of segment $4 \mathrm{~b} / 5$. Trisectionectomy was performed in eight patients $(5 \%)$, central bisectionectomy in three patients $(2 \%)$ and hemihepatectomy in five patients $(3 \%)$. Combined resection of adjacent organs was performed in six patients $(4 \%)$ of BDR group and included the pancreas $(n=3)$, duodenum $(n=1)$, and colon $(n=2)$ (Fig. 2). Of the 50 patients with T3 tumors, invasion into the liver $(n=30)$, serosa $(n=17)$ and bile duct $(n=3)$ were diagnoseded and documented.

The median follow-up period for BDR group was 50 months (range: 0-145 months) and for BDNR group was 80 months (range: 0-152 months). During the follow-up period, recurrence occurred in 64 patients $(43 \%)$. Local recurrences $(n=8)$ occurred at the liver resection margin $(n=4)$, hilar area $(n=3)$ and trocar site $(n=1)$.

Given the clinicopathologic heterogeneity (Table 1) among the two groups, a subgroup analysis was performed for those who underwent liver resection $(n=89)$ with or without BDR (Table 2). In this subset of patients, only eleven of 47 patients underwent BDR for suspected invasion.

While median operative time and postoperative hospital stay was significantly increased in the BDR group, complication rates were seemingly unaffected. Complications (according to Clavien-Dindo Classification) were comparable between BDR and BDNR group $(p=0.558)$. Among 10 (21\%) complications in BDR group, three were grade 1 and included ascites and seroma. One patient had

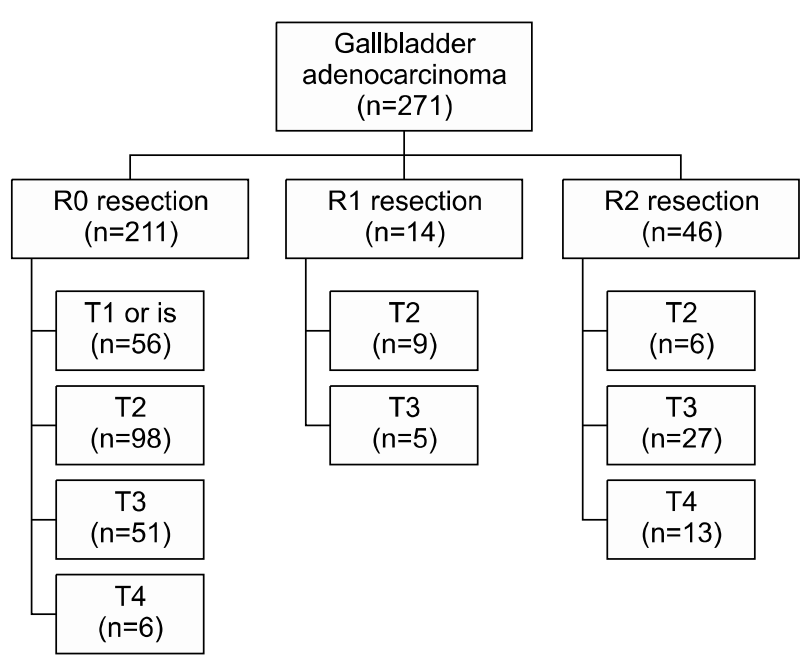

Fig. 1. Distribution of T-stage according to residual tumor. 
Table 1. Clinicopathologic characteristics

\begin{tabular}{|c|c|c|c|c|}
\hline Variables & & BDR group $(\mathrm{N}=54)$ & BDNR group $(\mathrm{N}=95)$ & $p$-value \\
\hline Median age, years (range) & & $61(38-82)$ & $62(48-80)$ & 0.358 \\
\hline Gender, $\mathrm{n}$ & Male & $23(43 \%)$ & $44(46 \%)$ & 0.661 \\
\hline Initial presentation & & & & 0.122 \\
\hline Incidental with reoperation & & $18(33 \%)$ & $44(46 \%)$ & \\
\hline Non-incidental & & $36(67 \%)$ & $51(54 \%)$ & \\
\hline Liver resections, $\mathrm{n}$ & & $47(87 \%)$ & $42(44 \%)$ & $<0.001$ \\
\hline \multicolumn{5}{|l|}{ Pathology, n } \\
\hline \multirow[t]{2}{*}{ T-stage } & $\mathrm{T} 2$ & $29(54 \%)$ & $70(74 \%)$ & 0.013 \\
\hline & $\mathrm{T} 3$ & $25(46 \%)$ & $25(26 \%)$ & \\
\hline \multirow[t]{3}{*}{$\mathrm{N}$ stage } & No & $30(56 \%)$ & $66(70 \%)$ & 0.049 \\
\hline & N1 & $11(20 \%)$ & $20(21 \%)$ & \\
\hline & $\mathrm{N} 2$ & $13(24 \%)$ & $9(10 \%)$ & \\
\hline \multirow[t]{4}{*}{ AJCC 7 th stage, $n$} & II & $16(30 \%)$ & $51(54 \%)$ & 0.011 \\
\hline & IIIA & $14(26 \%)$ & $15(16 \%)$ & \\
\hline & IIIB & $11(20 \%)$ & $20(21 \%)$ & \\
\hline & IVB & $13(24 \%)$ & $9(10 \%)$ & \\
\hline \multirow[t]{2}{*}{ Lymphovascular invasion } & Yes & $8(15 \%)$ & $16(17 \%)$ & 0.746 \\
\hline & No & $46(85 \%)$ & $79(83 \%)$ & \\
\hline \multirow[t]{2}{*}{ Perineural invasion } & Yes & $12(22 \%)$ & $9(10 \%)$ & 0.032 \\
\hline & No & $42(78 \%)$ & $86(91 \%)$ & \\
\hline \multirow[t]{4}{*}{ Differentiation } & Well & $8(15 \%)$ & $39(41 \%)$ & 0.003 \\
\hline & Moderate & $25(46 \%)$ & $38(40 \%)$ & \\
\hline & Poor & $10(19 \%)$ & $11(12 \%)$ & \\
\hline & Unknown & $11(20 \%)$ & $7(7 \%)$ & \\
\hline \multicolumn{5}{|c|}{ Median lymph nodes retrieved (Interquartile range) } \\
\hline \multicolumn{2}{|c|}{ All lymph nodes (except LN 16) } & $14.5(8-18.25)$ & $5(0-13)$ & $<0.001$ \\
\hline \multicolumn{2}{|l|}{ LN $7,8,9$} & $3(0-6)$ & $0(0-3)$ & $<0.001$ \\
\hline \multicolumn{2}{|l|}{$\mathrm{LN} 12 \mathrm{c}$} & $1(1-2)$ & $1(1-1)$ & 0.662 \\
\hline \multicolumn{2}{|l|}{$\mathrm{LN} 12 \mathrm{ec}$} & $3.5(1-5)$ & $1(0-4)$ & 0.005 \\
\hline \multicolumn{2}{|l|}{ LN 13} & $1(0-2)$ & $0(0-1)$ & 0.001 \\
\hline \multicolumn{2}{|l|}{ LN 16} & $3(0-6)$ & $0(0-5)$ & 0.031 \\
\hline \multicolumn{2}{|l|}{ Adjuvant therapy, $\mathrm{n}$} & $27(50 \%)$ & $47(50 \%)$ & 0.951 \\
\hline \multicolumn{2}{|l|}{ Recurrence, $\mathrm{n}$} & $26(48 \%)$ & $38(40 \%)$ & 0.334 \\
\hline
\end{tabular}

BDR group, bile duct resection group; BDNR group, bile duct non-resection group; LN 16, para-aortic lymph nodes; LN 7,8,9, lymph nodes around the gastrohepatic ligament; LN12c, pericholecystic lymph nodes; LN 12ec, lymph nodes around the hepatoduodenal ligament, excluding pericholecystic nodes; LN 13, retropancreatic lymph nodes

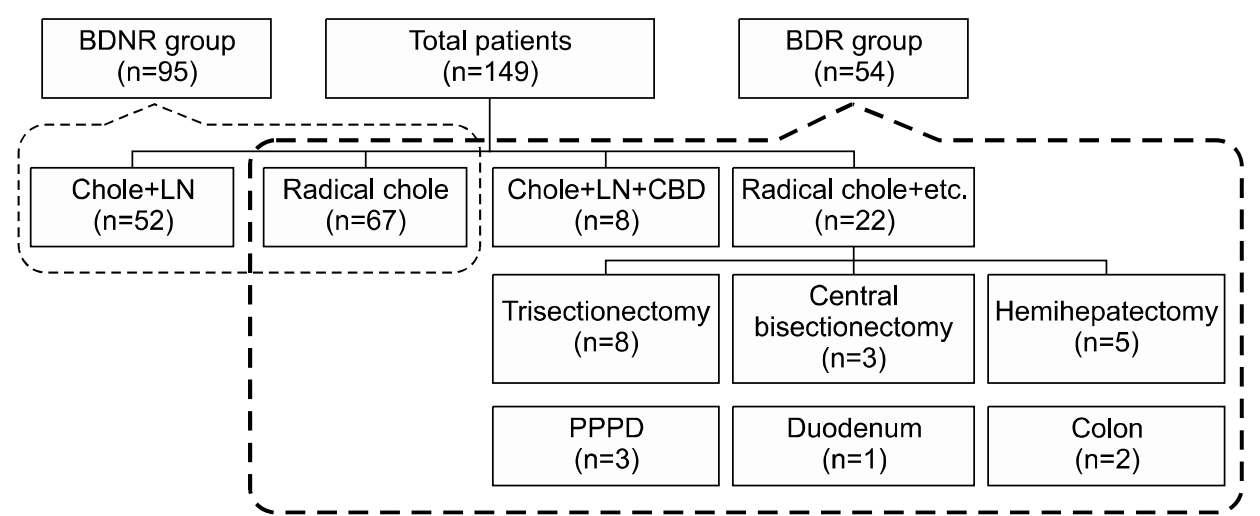

Fig. 2. Type of operative procedures. BDNR group, bile duct non-resection group; BDR group, bile duct resection group; Chole, cholecystectomy; LN, lymph node dissection; CBD, common bile duct resection; Radical chole+etc., Radical cholecystectomy and combined resection; PPPD, Pyloruspreserving pancreaticoduodenec- 
Table 2. Comparison between bile duct resection and bile duct non-resection groups for combined liver resected patients

\begin{tabular}{|c|c|c|c|c|}
\hline Variables & & BDR group $(\mathrm{N}=47)$ & BDNR group $(\mathrm{N}=42)$ & $p$-value \\
\hline Median age, years (range) & & $60(38-82)$ & $63(48-75)$ & 0.258 \\
\hline \multirow[t]{2}{*}{ Gender, $\mathrm{n}$} & Male & 19 & 22 & 0.259 \\
\hline & Female & 28 & 20 & \\
\hline Median operative time, min (range) & & $372(216-739)$ & $221(112-556)$ & $<0.001$ \\
\hline Median intraoperative blood loss, $\mathrm{ml}$ (range) & & $350(0-2300)$ & $275(0-2100)$ & 0.432 \\
\hline Complications, $\mathrm{n}$ & & $10(21 \%)$ & $5(12 \%)$ & 0.558 \\
\hline Median postoperative hospital stay, days (range) & & $14.5(7-43)$ & $12(7-83)$ & 0.025 \\
\hline \multirow[t]{2}{*}{ Differentiation, $\mathrm{n}$} & Well & $7(19 \%)$ & $15(39 \%)$ & 0.071 \\
\hline & Moderate/poor & $29(81 \%)$ & $24(62 \%)$ & \\
\hline Lymphovascular invasion, $\mathrm{n}$ & & $7(15 \%)$ & $5(12 \%)$ & 0.680 \\
\hline Perineural invasion, $\mathrm{n}$ & & $11(23 \%)$ & $4(10 \%)$ & 0.081 \\
\hline Lymph node metastasis, $\mathrm{n}$ & & $20(43 \%)$ & $13(31 \%)$ & 0.258 \\
\hline \multirow[t]{2}{*}{ T-stage, $\mathrm{n}$} & $\mathrm{T} 2$ & $24(51 \%)$ & $26(62 \%)$ & 0.303 \\
\hline & $\mathrm{T} 3$ & $23(49 \%)$ & $16(38 \%)$ & \\
\hline \multirow[t]{4}{*}{ AJCC $7^{\text {th }}$ stage, $\mathrm{n}$} & II & $14(30 \%)$ & $20(48 \%)$ & 0.105 \\
\hline & IIIA & $13(28 \%)$ & $9(21 \%)$ & \\
\hline & IIIB & $9(19 \%)$ & $10(24 \%)$ & \\
\hline & IVB & $11(23 \%)$ & $3(7 \%)$ & \\
\hline \multicolumn{5}{|c|}{ Median lymph nodes retrieved (Interquartile range) } \\
\hline All lymph nodes (except LN 16) & & $15(8.00-19.00)$ & $9(4.75-15.25)$ & 0.006 \\
\hline LN $7,8,9$ & & $4(0-6)$ & $1.50(0-5.25)$ & 0.115 \\
\hline $\mathrm{LN} 12 \mathrm{c}$ & & $1(1-2)$ & $1(1-1.75)$ & 0.742 \\
\hline $\mathrm{LN} 12 \mathrm{ec}$ & & $3(1-5)$ & $2(0-5.25)$ & 0.379 \\
\hline LN 13 & & $1(0-2)$ & $0(0-1)$ & 0.013 \\
\hline LN 16 & & $3(0-6)$ & $0(0-6)$ & 0.302 \\
\hline
\end{tabular}

BDR group, bile duct resection group; BDNR group, bile duct non-resection group; LN 16, para-aortic lymph nodes; LN 7,8,9, lymph nodes around the gastrohepatic ligament; LN12c, pericholecystic lymph nodes; LN 12ec, lymph nodes around the hepatoduodenal ligament, excluding pericholecystic nodes; LN 13, retropancreatic lymph nodes

a grade 2 complication with chyle drainage. Four patients had grade 3 a complications and included pigtail insertions for fluid collection. Remaining two patients had grade $3 \mathrm{~b}$ complications due to wound repair under general anesthesia.

Para-aortic lymph node (LN 16) dissection was performed more frequently in the BDR group (29 patients $(62 \%)$ vs. 18 patients $(43 \%), p=0.032)$.

Twenty-two patients $(50 \%)$ in the BDR group and 22 patients $(52 \%)$ in the BDNR group received adjuvant therapy, $p=0.600$.

In terms of recurrence, there was no significant difference between the two groups (21 patients $(45 \%)$ in the BDR group vs. sixteen patients $(38 \%)$ in the BDNR group, $p=0.529$. Most of the recurrences were distant metastasis.

At the end of the follow-up period, 83 patients (56\%) were still alive. There was a follow-up loss of three patients $(2 \%)$ after the discharge from the hospital. The 5-year disease-free survival and overall survival rates were $55 \%$ and $54 \%$, respectively. The 5 -year overall survival rates of Stages II, IIIA, IIIB and IVB (according to cancer stage using the American Joint Committee on Cancer (AJCC) $7^{\text {th }}$ Edition Staging) were $69 \%, 43 \%$, 51\%, and $16 \%$, respectively. There were significant differences of overall survival rate according to the TNM stage, except between stage IIIA and IIIB $(p=0.460)$. Comparisons of survival rates (according to TNM) stage are shown in Fig. 3.

According to the survival analysis for bile duct resection, there was no evidence of survival benefit of bile duct resection in each of cancer stage (Fig. 4). Further survival analysis for liver resected patients has also shown no significant role of bile duct resection in both overall survival and disease-free survival (Fig. 5).

In univariate analysis for disease-free survival, bile duct resection $(p=0.048)$ was one indicator of poor survival outcome. However, in multivariate analyses, lymph node 
A

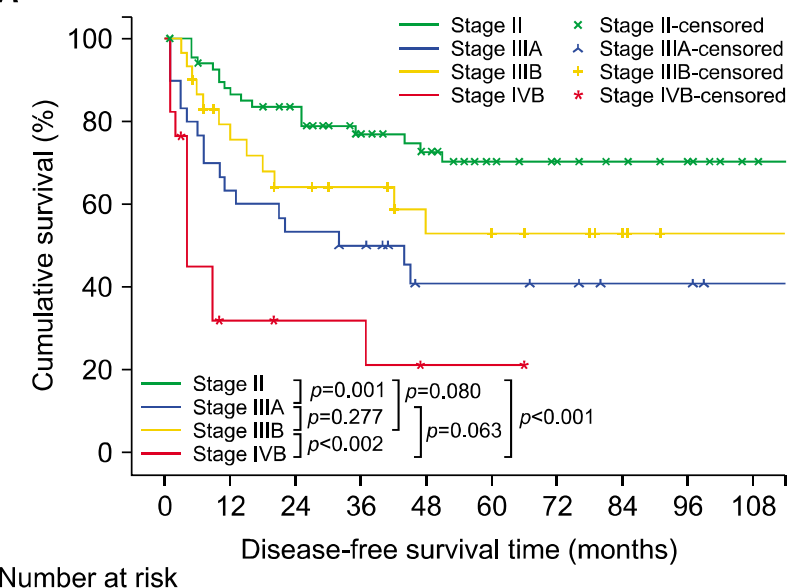

$\begin{array}{lllllllllll}\text { Stage II } & 69 & 58 & 53 & 38 & 33 & 22 & 18 & 15 & 12 & 06\end{array}$

$\begin{array}{lllllllllll}\text { Stage IIIA } & 30 & 19 & 16 & 14 & 07 & 07 & 05 & 04 & 04 & 02\end{array}$

$\begin{array}{lllllllllll}\text { Stage IIIB } & 30 & 20 & 16 & 13 & 09 & 08 & 07 & 04 & 02 & 02\end{array}$

Stage IVB $17 \quad 04 \quad 03 \quad 03 \quad 01 \quad 01$
B

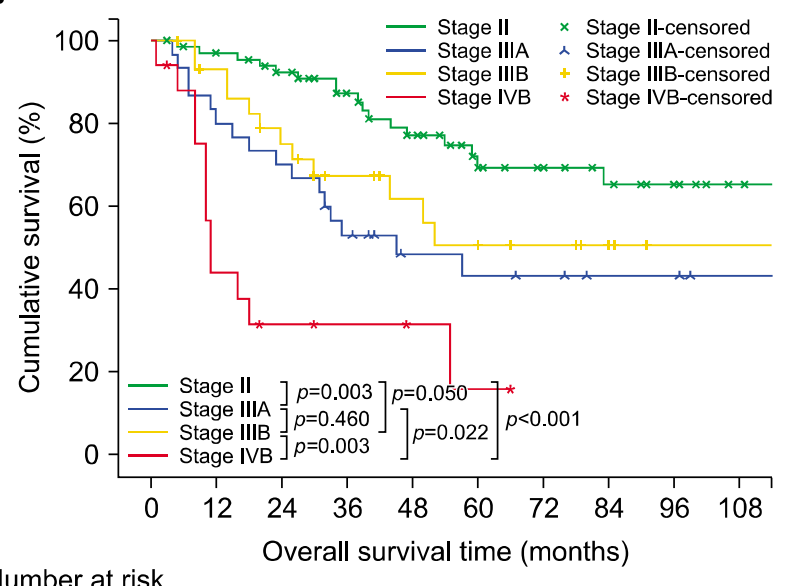

Number at risk

$\begin{array}{lllllllllll}\text { Stage II } & 69 & 64 & 58 & 44 & 36 & 24 & 20 & 16 & 12 & 06\end{array}$

$\begin{array}{lllllllllll}\text { Stage IIIA } & 30 & 24 & 21 & 15 & 09 & 08 & 07 & 05 & 05 & 03\end{array}$

$\begin{array}{lllllllllll}\text { Stage IIIB } & 30 & 26 & 20 & 14 & 11 & 08 & 07 & 04 & 02 & 02\end{array}$

$\begin{array}{lllllll}\text { Stage IVB } & 17 & 07 & 04 & 03 & 02 & 01\end{array}$

Fig. 3. Survival curves according to American Joint Committee on Cancer Staging Manuam $7^{\text {th }}$ edition TNM stage. (A) Disease-free survival. (B) Overall survival.

metastasis $(p=0.021)$, T3 stage vs. T2 stage $(p=0.001)$, and total retrieved lymph nodes $<6$ vs. $\geq 6(p<0.001)$ were the independent prognostic factors for poor survival outcome (Table 3). In multivariate analysis for overall survival, lymph node metastasis, T3 stage, and the total number of retrieved lymph nodes $<6$ were the independent prognostic factors of poor survival outcome (Table 4).

\section{DISCUSSION}

The optimal extent of resection in advanced gallbladder cancer patients remains a debated issue. Chiefly, the clinical significance of concomitant bile duct resection remains controversial. Kokudo et al. ${ }^{7}$ reported no appreciable survival benefit secondary to bile duct resection in patients with LN metastasis. Sakamoto et al. ${ }^{8}$ also reported that there was no perceptible survival benefit associated with bile duct resection in patients with $\geq \mathrm{T} 2$ gallbladder cancer. Araida et al. ${ }^{6}$ analyzed 838 gallbladder cancer patients and reported that no survival difference resulted from bile duct resection in patients without direct infiltration of the hepatoduodenal ligament.

In the current study, there were no significant, documented differences in the overall survival between the BDR group and BDNR group, even though the BDR group patients had more advanced tumors than the BDNR group patients. Advanced T-stage, presence of LN meta- stasis and total $\mathrm{LN}$ count of $<6$ were the independent prognostic indicators of poor survival outcome in the multivariate analysis. In other study groups, lymphovascular invasion, perineural invasion, $\mathrm{LN}$ metastasis, total $\mathrm{LN}$ count of $<6$ and poor differentiation have been reported to be significant prognostic factors in patients with gallbladder cancer. ${ }^{3,9,10}$

Adequate LN assessment is important in patients with gastrointestinal cancers, ${ }^{12-14}$ because insufficient lymph node dissection during surgery impedes accurate staging. Ito et al. $^{3}$ reported that the minimum $\mathrm{LN}$ requirement for adequate gallbladder cancer staging was six nodes. In our study, the LN count of $<6$ was also the prognostic factor for poor survival outcome in gallbladder cancer patients (T2 and T3 stage) who received R0 resection. The BDR group had more LNs removed than the BDNR group. Specifically, the LNs around the retropancreatic area were more frequently retrieved in the BDR group. Although bile duct resection did not affect the overall survival of gallbladder cancer patients, bile duct resection could be helpful for more accurately staging the disease.

Anatomically, the lymphatics around the hepatoduodenal ligament are the first lymphatic channels draining the gallbladder. ${ }^{15}$ Tumor cell-spread into the hepatoduodenal ligament is very frequently observed in advanced gallbladder cancer. In 2014, pathologists in Japan reported $70.6 \%$ lymphatic/venous/perineural invasion of gallbladder 
A

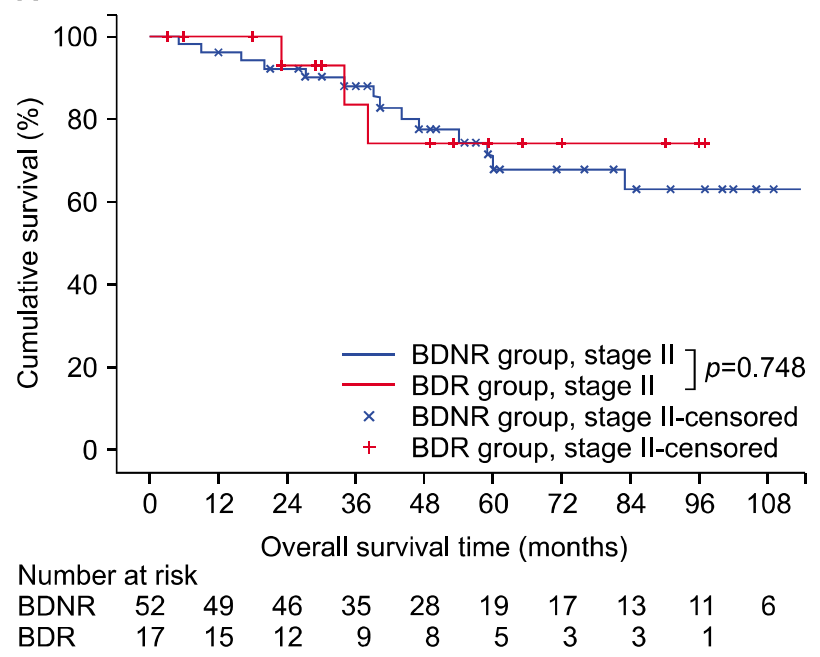

C

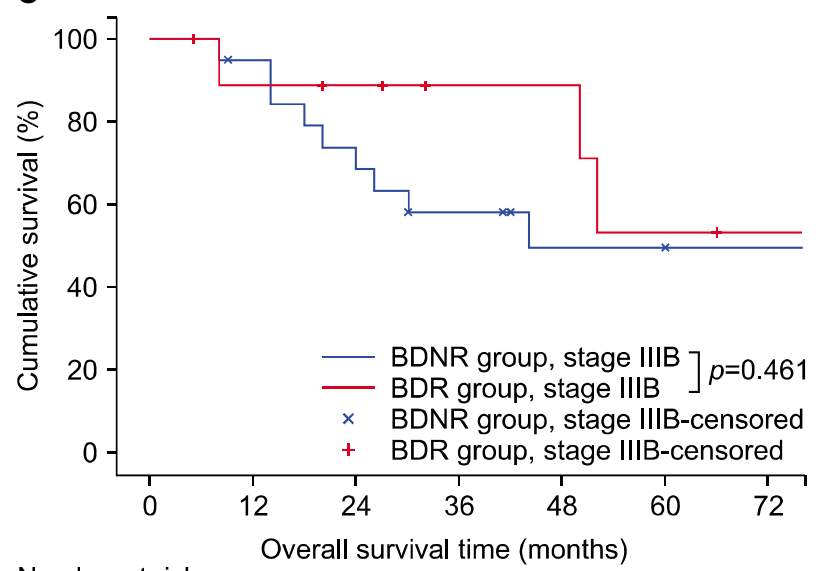

Number at risk

$\begin{array}{lrrrrrrr}\text { BDNR } & 20 & 18 & 13 & 9 & 6 & 5 & 3 \\ \text { BDR } & 10 & 8 & 7 & 5 & 5 & 3 & 1\end{array}$
B

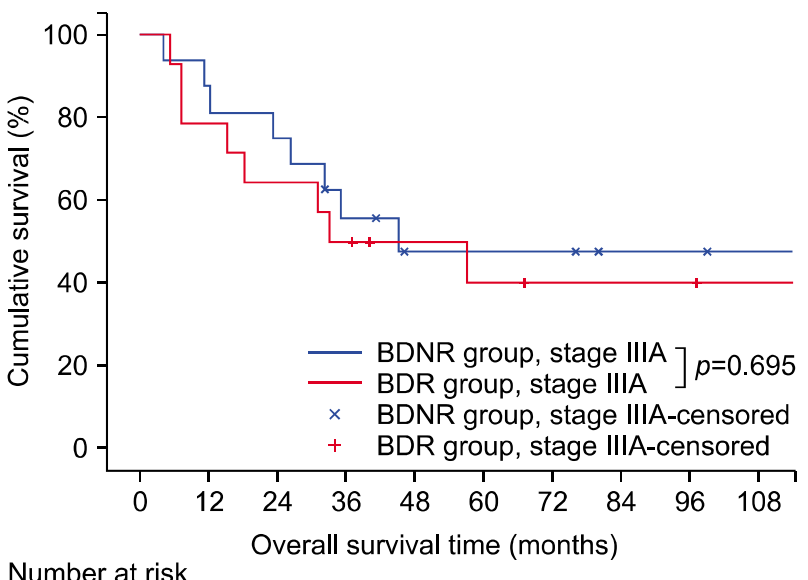

Number at risk

$\begin{array}{lrrrrrrrrrr}\text { BDNR } & 16 & 13 & 12 & 8 & 4 & 4 & 4 & 2 & 2 & 1 \\ \text { BDR } & 14 & 11 & 9 & 7 & 5 & 4 & 3 & 3 & 3 & 2\end{array}$

D

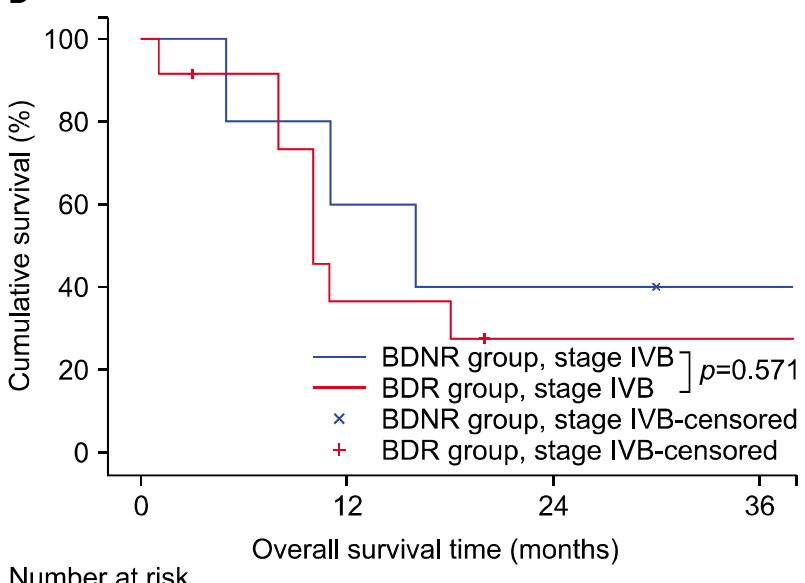

Number at risk

BDNR 5

BDR 12
3

4
2
2

1

Fig. 4. Survival curves comparing the BDR and BDNR groups. (A) Overall survival for Stage II. (B) Overall survival for Stage IIIA. (C) Overall survival for Stage IIIB. (D) Overall survival for Stage IVB. BDNR group, Bile duct non-resection group; BDR group, Bile duct resection group.

A

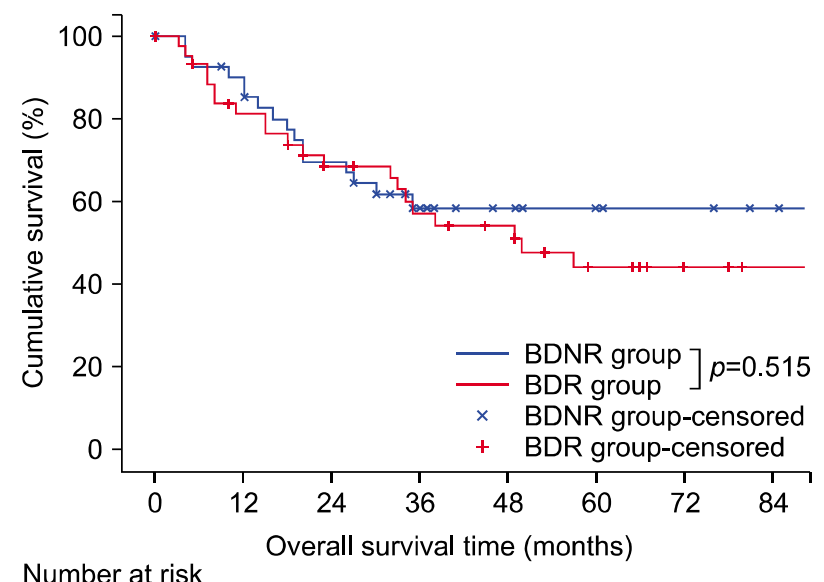

Number at risk

$\begin{array}{lllllllll}\text { BDNR } & 42 & 33 & 27 & 16 & 11 & 8 & 7 & 4\end{array}$
B

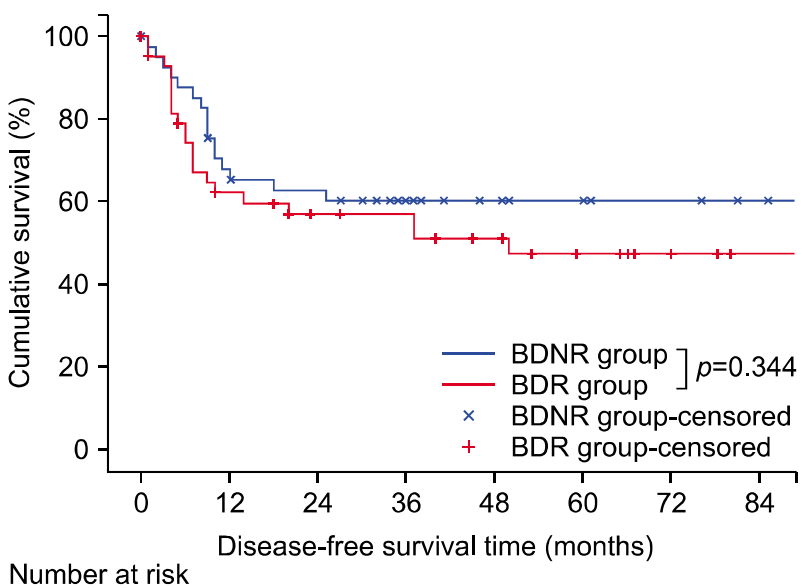

$\begin{array}{lllllllll}\text { BDNR } & 42 & 27 & 24 & 17 & 11 & 9 & 7 & 4\end{array}$

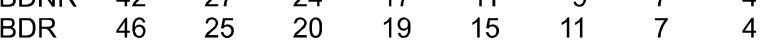

Fig. 5. Survival curves comparing the BDR and BDNR groups for liver resection patients. (A) Overall survival. (B) Disease-free survival. BDNR group, Bile duct non-resection group; BDR group, Bile duct resection group. 
Table 3. Univariate and multivariate analyses of prognostic factors for disease-free survival

\begin{tabular}{|c|c|c|c|c|}
\hline \multirow{2}{*}{ Variables } & \multicolumn{2}{|c|}{ Univariate analysis } & \multicolumn{2}{|c|}{ Multivariate analysis } \\
\hline & HR $(95 \%$ CI $)$ & $p$-value & HR $(95 \%$ CI $)$ & $p$-value \\
\hline \multicolumn{5}{|l|}{ Age, years (n) } \\
\hline$<65$ (99) vs. $\geq 65$ (50) & $1.012(0.607-1.686)$ & 0.964 & & \\
\hline \multicolumn{5}{|l|}{$\operatorname{Sex}(n)$} \\
\hline Male (67) vs. Female (82) & $1.247(0.749-2.078)$ & 0.391 & & \\
\hline \multicolumn{5}{|l|}{ Bile duct resection $(\mathrm{n})$} \\
\hline Yes (54) vs. No (95) & $1.668(0.994-2.799)$ & 0.048 & $1.743(0.973-3.121)$ & 0.062 \\
\hline \multicolumn{5}{|l|}{ Liver resection (n) } \\
\hline Yes (89) vs. No (60) & $1.472(0.863-2.511)$ & 0.150 & & \\
\hline \multicolumn{5}{|l|}{ Para-aortic LN dissection (n) } \\
\hline Yes (64) vs. No (81) & $0.784(0.452-1.359)$ & 0.380 & & \\
\hline \multicolumn{5}{|l|}{ Adjuvant therapy (n) } \\
\hline Yes (74) vs. No (75) & $2.035(1.200-3.451)$ & 0.007 & $1.538(0.890-2.658)$ & 0.123 \\
\hline \multicolumn{5}{|l|}{ Size, cm (n) } \\
\hline$<3$ (43) vs. $\geq 3$ (56) & $0.706(0.356-1.399)$ & 0.313 & & \\
\hline \multicolumn{5}{|l|}{ Differentiation (n) } \\
\hline WD (47) vs. MD to PD (84) & $0.600(0.325-1.111)$ & 0.097 & & \\
\hline \multicolumn{5}{|l|}{ Lymphovascular invasion (n) } \\
\hline Pos. (24) vs. Neg. (125) & $1.926\left(1.056^{-3.513)}\right.$ & 0.028 & $1.938(0.997-3.767)$ & 0.051 \\
\hline \multicolumn{5}{|l|}{ Perineural invasion (n) } \\
\hline Pos. (21) vs. Neg. (128) & $1.886(0.977-3.639)$ & 0.059 & & \\
\hline \multicolumn{5}{|l|}{ Lymph node metastasis (n) } \\
\hline Pos. (53) vs. Neg. (96) & $1.945(1.154-3.277)$ & 0.010 & $1.978(1.111-3.522)$ & 0.021 \\
\hline \multicolumn{5}{|l|}{ T-stage $(n)$} \\
\hline T3 (50) vs. T2 (99) & $2.870(1.719-4.793)$ & $<0.001$ & $2.497(1.466-4.251)$ & 0.001 \\
\hline \multicolumn{5}{|l|}{ Total retrieved lymph nodes (n) } \\
\hline$<6(58)$ vs. $\geq 6(91)$ & $1.709(1.020-2.865)$ & 0.038 & $2.930(1.605-5.349)$ & $<0.001$ \\
\hline
\end{tabular}

HR, hazard ratio; 95\% CI, 95\% confidence interval; WD, well differentiated; MD, moderately differentiated; PD, poorly differentiated; Pos., positive; Neg., negative

cancer (T2 and T3). ${ }^{16}$ In our study, the BDR group had more lymph nodes retrieved around the retropancreatic area vs. the BDNR group. While other lymph node stations did not yield more retrieved lymph nodes for the BDR group, total number of lymph nodes retrieved was significantly higher in the BDR group. These results indicate that lymph node dissection with bile duct resection allow more thorough removal of lymph nodes without leaving remnant lymph nodes and connective tissue around the hepatoduodenal ligament.

Gallbladder cancer can spread in a skipped manner. Shimizu et al. ${ }^{17}$ in pathologic analysis of 50 patients with advanced gallbladder cancer, reported that $30(60 \%)$ patients with the hepatoduodenal ligament invasion including five patients with skipped lesion from the primary tumor. Among patients with hepatoduodenal ligament invasion, 25 (83\%) patients showed cancer cells in extrahepatic bile duct and 21 (70\%) patients showed occult microscopic extension. Ogura et al. ${ }^{18}$ also reported dis- continuation of tumor invasion into the hepatic parenchyma. In terms of these findings, BDR has a potential benefit of eradicating occult tumor spread at the common bile duct from gallbladder cancer because of the possibility of skipped lesions not involving the cystic duct margin. We could not, however, affirm any positive effect on the long-term survival rate attributable to, or associated with, BDR. As such, it may be that the role of BDR may be limited to improved staging of gallbladder cancer as discussed in our study.

Too, the patients in the BDR group were afflicted with more aggressive cancer than the BDNR group and accordingly, surgical resection in the BDR group was also more extensive than in the BDNR group. To minimize the bias from extensive surgical resection and aggressive cancer in BDR group, only the patients with liver resection were further analyzed. Bile duct resection involved longer operative time and long postoperative hospital stays. These findings somewhat echo the findings reported by another 
Table 4. Univariate and multivariate analyses of prognostic factors for overall survival

\begin{tabular}{|c|c|c|c|c|}
\hline \multirow{2}{*}{ Variables } & \multicolumn{2}{|c|}{ Univariate analysis } & \multicolumn{2}{|c|}{ Multivariate analysis } \\
\hline & HR $(95 \% \mathrm{CI})$ & $p$-value & $\mathrm{HR}(95 \% \mathrm{CI})$ & $p$-value \\
\hline \multicolumn{5}{|l|}{ Age, year } \\
\hline$<65$ vs. $\geq 65$ & $0.94\left(0.56^{-1.58)}\right.$ & 0.82 & & \\
\hline \multicolumn{5}{|l|}{ Sex } \\
\hline Male vs. Female & $1.17(0.70-1.97)$ & 0.55 & & \\
\hline \multicolumn{5}{|l|}{ Body mass index, $\mathrm{kg} / \mathrm{m}^{2}$} \\
\hline \multicolumn{5}{|l|}{ Bile duct resection } \\
\hline \multicolumn{5}{|l|}{ Liver resection } \\
\hline Yes vs. No & $1.50(0.88-2.57)$ & 0.14 & & \\
\hline \multicolumn{5}{|l|}{ Para-aortic LN dissection } \\
\hline \multicolumn{5}{|l|}{ Adjuvant therapy } \\
\hline Yes vs. No & $1.56(0.92-2.65)$ & 0.10 & & \\
\hline \multicolumn{5}{|l|}{ Size, cm } \\
\hline$<3$ vs. $\geq 3$ & $0.63(0.32-1.27)$ & 0.20 & & \\
\hline \multicolumn{5}{|l|}{ Differentiation } \\
\hline WD vs. MD to PD & $0.63(0.34-1.16)$ & 0.14 & & \\
\hline \multicolumn{5}{|l|}{ Lymphovascular invasion } \\
\hline Positive vs. Negative & $1.83(0.99-3.41)$ & 0.06 & & \\
\hline \multicolumn{5}{|l|}{ Perineural invasion } \\
\hline Positive vs. Negative & $1.99(1.03-3.86)$ & 0.04 & $1.56(0.78-3.10)$ & 0.21 \\
\hline \multicolumn{5}{|l|}{ Lymph node metastasis } \\
\hline Positive vs. Negative & $1.95(1.15-3.28)$ & 0.01 & $2.59(1.47-4.54)$ & $<0.01$ \\
\hline \multicolumn{5}{|l|}{ T-stage } \\
\hline T3 vs. T2 & $3.12(1.85-5.27)$ & $<0.01$ & $3.14(1.86-5.32)$ & $<0.01$ \\
\hline \multicolumn{5}{|c|}{ Total retrieved LN number } \\
\hline$<6$ vs. $\geq 6$ & $1.87\left(1.10^{-3.19)}\right.$ & 0.02 & $2.51(1.44-4.39)$ & $<0.01$ \\
\hline
\end{tabular}

HR, hazard ratio; 95\% CI, 95\% confidence interval; WD, well differentiated; MD, moderately differentiated; PD, poorly differentiated; LN, lymph node

study group. ${ }^{9}$ However, we detected no relationship between bile duct resection and the postoperative complication rate documented by our study, even though bile duct resection always required bilioenteric anastomosis. Adverse effects of bile duct resection were almost always limited to the immediate postoperative period.

Recurrence of gallbladder cancer is more likely to involve a distant site and frequently occurs in early-stage disease. $^{19,20}$ The peritoneum, liver and retroperitoneal lymph nodes tend to be the most common recurrence sites of a primary gallbladder cancer. ${ }^{20}$ This recurrence pattern has tended to obscure the potential beneficial effect of bile duct resection in obviating a local recurrence. Moreover, patients with advanced cancer received adjuvant therapy, which has reported favorable results with regard to the survival benefits for gallbladder cancer. ${ }^{21,22}$ The recurrence rate in the BDR group was not significantly different from that of the BDNR group in this study. To estimate the relationship between the recurrence rate and bile duct resection, the effectiveness of bile duct resection for accurate lymph node dissection must be evaluated further.

About half of the patients who participated in this study received adjuvant therapy. Thirty-three patients in the BDR group and 22 patients in BDNR group belonged to $7^{\text {th }}$ edition AJCC stage of greater than IIIA group. With 22 patients in each group undergoing adjuvant therapy, eleven patients in the BDR group did not receive adjuvant therapy due to patient refusal or poor performance status. This may have confounded the results in survival analysis. Moreover, results of this study may have been influenced by heterogeneous nature of the adjuvant therapy. Due to limited size of this study, further subgroup analysis on different regimens used was not possible. With more uniform adjuvant treatment, better analysis on the efficacy of bile duct resection may by possible.

Bile duct resection seems to only influence staging and 
no benefits on survival have been revealed from this study. Accurate staging in gallbladder cancer is still important. Lack of survival benefit in bile duct resection may be influenced by lack of uniformity in adjuvant treatment. Further evaluation of bile duct resection, with homogenous adjuvant treatment regimen, should be considered viable treatment options, for therapeutic and diagnostic purposes, and to gain further insights into survival benefits.

In conclusion, advanced T-stage, LN metastasis, and LN count $<6$ were the independent prognostic factors for overall survival and disease-free survival in patients with T2 and T3 gallbladder cancer. The BDR group had more lymph nodes retrieved vs. the BDNR group, and bile duct resection did not increase complication rate. The role of bile duct resection may be limited to improved staging and without affording any actual long-term survival benefit, based upon the current study. However, without any documented, significant increase in morbidity of the BDR group, bile duct resection should be actively considered as in patients with suspicious invasion around hepatoduodenal ligament.

\section{REFERENCES}

1. Lazcano-Ponce EC, Miquel JF, Muñoz N, Herrero R, Ferrecio C, Wistuba II, et al. Epidemiology and molecular pathology of gallbladder cancer. CA Cancer J Clin 2001;51:349-364.

2. Hueman MT, Vollmer CM Jr, Pawlik TM. Evolving treatment strategies for gallbladder cancer. Ann Surg Oncol 2009;16:2101-2115.

3. Ito $\mathrm{H}$, Ito $\mathrm{K}$, D'Angelica M, Gonen M, Klimstra D, Allen P, et al. Accurate staging for gallbladder cancer: implications for surgical therapy and pathological assessment. Ann Surg 2011;254: 320-325.

4. Higuchi R, Ota T, Araida T, Kajiyama H, Yazawa T, Furukawa $\mathrm{T}$, et al. Surgical approaches to advanced gallbladder cancer: a 40-year single-institution study of prognostic factors and resectability. Ann Surg Oncol 2014;21:4308-4316.

5. Benson AB 3rd, Abrams TA, Ben-Josef E, Bloomston PM, Botha JF, Clary BM, et al. NCCN clinical practice guidelines in oncology: hepatobiliary cancers. J Natl Compr Canc Netw 2009; 7:350-391.

6. Araida T, Higuchi R, Hamano M, Kodera Y, Takeshita N, Ota $\mathrm{T}$, et al. Should the extrahepatic bile duct be resected or preserved in R0 radical surgery for advanced gallbladder carcinoma? Results of a Japanese Society of Biliary Surgery Survey: a multicenter study. Surg Today 2009;39:770-779.

7. Kokudo N, Makuuchi M, Natori T, Sakamoto Y, Yamamoto J,
Seki M, et al. Strategies for surgical treatment of gallbladder carcinoma based on information available before resection. Arch Surg 2003;138:741-750; discussion 750.

8. Sakamoto Y, Kosuge T, Shimada K, Sano T, Hibi T, Yamamoto $\mathrm{J}$, et al. Clinical significance of extrahepatic bile duct resection for advanced gallbladder cancer. J Surg Oncol 2006;94:298-306.

9. Choi SB, Han HJ, Kim WB, Song TJ, Suh SO, Choi SY. Surgical strategy for T2 and T3 gallbladder cancer: is extrahepatic bile duct resection always necessary? Langenbecks Arch Surg 2013;398:1137-1144.

10. Lim H, Seo DW, Park DH, Lee SS, Lee SK, Kim MH, et al. Prognostic factors in patients with gallbladder cancer after surgical resection: analysis of 279 operated patients. J Clin Gastroenterol 2013;47:443-448.

11. Clavien PA, Barkun J, de Oliveira ML, Vauthey JN, Dindo D, Schulick RD, et al. The Clavien-Dindo classification of surgical complications: five-year experience. Ann Surg 2009;250:187-196.

12. Yoshikawa T, Sasako M, Sano T, Nashimoto A, Kurita A, Tsujinaka T, et al. Stage migration caused by D2 dissection with para-aortic lymphadenectomy for gastric cancer from the results of a prospective randomized controlled trial. Br J Surg 2006;93: 1526-1529.

13. Pawlik TM, Gleisner AL, Cameron JL, Winter JM, Assumpcao $\mathrm{L}$, Lillemoe KD, et al. Prognostic relevance of lymph node ratio following pancreaticoduodenectomy for pancreatic cancer. Surgery 2007;141:610-618.

14. Kim YW, Kim NK, Min BS, Lee KY, Sohn SK, Cho CH, et al. The prognostic impact of the number of lymph nodes retrieved after neoadjuvant chemoradiotherapy with mesorectal excision for rectal cancer. J Surg Oncol 2009;100:1-7.

15. Ito M, Mishima $Y$, Sato T. An anatomical study of the lymphatic drainage of the gallbladder. Surg Radiol Anat 1991;13:89-104.

16. Kijima H, Wu Y, Yosizawa T, Suzuki T, Tsugeno Y, Haga T, et al. Pathological characteristics of early to advanced gallbladder carcinoma and extrahepatic cholangiocarcinoma. J Hepatobiliary Pancreat Sci 2014;21:453-458.

17. Shimizu Y, Ohtsuka M, Ito H, Kimura F, Shimizu H, Togawa A, et al. Should the extrahepatic bile duct be resected for locally advanced gallbladder cancer? Surgery 2004;136:1012-1017; discussion 1018.

18. Ogura Y, Tabata M, Kawarada Y, Mizumoto R. Effect of hepatic invasion on the choice of hepatic resection for advanced carcinoma of the gallbladder: histologic analysis of 32 surgical cases. World J Surg 1998;22:262-266; discussion 266-267.

19. Jung SJ, Woo SM, Park HK, Lee WJ, Han MA, Han SS, et al. Patterns of initial disease recurrence after resection of biliary tract cancer. Oncology 2012;83:83-90.

20. Jarnagin WR, Ruo L, Little SA, Klimstra D, D'Angelica M, DeMatteo RP, et al. Patterns of initial disease recurrence after resection of gallbladder carcinoma and hilar cholangiocarcinoma: implications for adjuvant therapeutic strategies. Cancer 2003;98: 1689-1700.

21. Gold DG, Miller RC, Haddock MG, Gunderson LL, Quevedo F, Donohue JH, et al. Adjuvant therapy for gallbladder carcinoma: the Mayo Clinic Experience. Int J Radiat Oncol Biol Phys 2009;75:150-155.

22. Kim K, Chie EK, Jang JY, Kim SW, Han SW, Oh DY, et al. Postoperative chemoradiotherapy for gallbladder cancer. Strahlenther Onkol 2012;188:388-392. 